\title{
Effect of Working Pressure and Substrate Bias on Phase Formation and Microstructure of Cr-Al-N Coatings
}

\author{
Seon-A Choi, Seong-Won Kim, Sung-Min Lee, Hyung-Tae Kim, and Yoon-Suk $\mathrm{Oh}^{\dagger}$ \\ Department of Engineering Ceramic Center, Korea Institute of Ceramic and Engineering Technology, Icheon 17303, Korea \\ (Received August 7, 2017; Revised September 21, September 28, 2017; Accepted September 28, 2017)
}

\begin{abstract}
With different working pressures and substrate biases, Cr-Al-N coatings were deposited by hybrid physical vapor deposition (PVD) method, consisting of unbalanced magnetron (UBM) sputtering and arc ion plating (AIP) processes. Cr and Al targets were used for the arc ion plating and the sputtering process, respectively. Phase analysis, and composition, binding energy, and microstructural analyses were performed using X-ray diffraction (XRD), X-ray photoelectron spectroscopy (XPS), and field emission scanning electron microscopy (FESEM), respectively. Surface droplet size of Cr-Al-N coatings was found to decrease with increasing substrate bias. A decrease of the deposition rate of Cr-Al-N films was expected due to the increase of substrate bias. The coatings were grown with textured $\mathrm{CrN}$ phase and (111), (200), and (220) planes. X-ray diffraction data show that all Cr-Al-N coatings shifted to lower diffraction angles due to the addition of $\mathrm{Al}$. The XPS results were used to determine the $\mathrm{Cr}_{2} \mathrm{~N}, \mathrm{CrN}$, and $(\mathrm{Cr}, \mathrm{Al}) \mathrm{N}$ binding energies. The compositions of the Cr-Al-N films were measured by XPS to be $\mathrm{Cr} 23.2 \sim 36.9$ at\%, Al 30.1 40.3 at\%, and N 31.3 38.6 at\%.
\end{abstract}

Key words : Cr-Al-N, Hard coating, Hybrid physical vapor deposition, Arc ion plating, Unbalanced magnetron sputtering

\section{Introduction}

$\mathrm{T}$ iN and $\mathrm{CrN}$ materials are used as a form of coating to cutting tools and precision machine parts in the machining industry due to their considerable wear and corrosion resistance, respectively for cost saving, productivity, and quality improvements. However, increased interest in issues concerning energy and the environment, for a sustainable society, the alternative machining methods such as minimum quantity lubrication and dry machining have been presented to reduce the usage of pollutants like lubricants in machining processing. Therefor the studies are being carried out regarding materials that can be used in harsh operational environments. ${ }^{1-3)}$ Recently, compared to simple materials such as $\mathrm{TiN}$ and $\mathrm{CrN}$, enhancement of physical properties including oxidation resistance and hardness was observed for composite coatings in which $\mathrm{Al}$, Si, and $\mathrm{C}$ were added to TiN and $\mathrm{CrN}^{4}{ }^{\text {) }}$

Among such composite coatings, CrAlN coating, in which $\mathrm{Al}$ was added to $\mathrm{CrN}$, was shown the higher hardness, lower coefficient of friction, and improved oxidation resistance compared to the conventional $\mathrm{CrN}$ coating. ${ }^{5,6)}$ Metallic nitride coatings with $\mathrm{NaCl}$ structure, such as TiN and $\mathrm{CrN}$, have been reported to have excellent mechanical properties. ${ }^{7)} \mathrm{CrN}$ has a high solubility with regard to $\mathrm{Al}$ (maximum

\footnotetext{
Corresponding author: Yoon-Suk Oh

E-mail : ysoh30@kicet.re.kr

Tel : +82-31-645-1442 Fax : +82-31-645-1492
}

of $77 \mathrm{at} \%)$. If $\mathrm{Al}$ penetrates within the $\mathrm{CrN}$ lattice above the maximum solubility, the structurure change is to the B4wurtzite structure. ${ }^{8)}$ Since Cr-Al-N coating with $0.6 \sim 0.7$ of $\mathrm{Al} / \mathrm{Cr}$, due to the $\mathrm{NaCl}$ structure of the coating, has more $\mathrm{CrN}$ bonding than that in $\mathrm{AlN}$, the mechanical properties of $\mathrm{CrN}$ are maintained and oxidation resistance is exhibited due to $\mathrm{Al}$. However, when the $\mathrm{Al}$ content increases, more AlN (B4-wurtzite) can be formed and increases the AlN bonding more than $\mathrm{CrN}$ bonding, which can cause the decrease of hardness. ${ }^{5-8)}$ However, there have been studies that the addition of $\mathrm{Al}$ to $\mathrm{CrAlN}$ coating within the $\mathrm{Al}$ content range that does not lead to hardness can lead to the decrease of particle size of coating, consequently affecting the hardness. ${ }^{9,10)}$ From above, the prediction of the mechanical properties of a coating film, such as the hardness and the oxidation resistance, might be possible through the observation of the phase formation and microstructure of coating.

Various physical vapor deposition (PVD) methods including evaporation deposition, ion plating, and sputtering are used as the major processes for films and hard coatings deposition; the major factors of PVD that affect to the film formation include the deposition pressure, distance between the target and specimen, applied power, and bias, etc.. ${ }^{11-17)}$ The ratio of the reactive gas for the reactive coating process an affects to the phase formation of the coating film and the target poisoning phenomenon, resulting in a change of the surface microstructure of coating. ${ }^{18,19)}$ Bias affects the coating deposition rate and the microstructure, and the studies 
on the coating phase and microstructure as affected by such process factors have been carried out. ${ }^{2,20)}$

In this study, Cr-Al-N coating was fabricated using the hybrid PVD method, which combines the arc ion plating and unbalanced magnetron sputtering methods. It was reported that the deposition pressure can affect to the coating density and phase formation and that the bias voltage (phase formation) affects the density of the droplets formed on the coating surface and the physical properties of the coating. ${ }^{21,22)} \mathrm{A}$ gas mixture of argon and nitrogen was used to investigate the phase formation and microstructure of the Cr-Al-N coating according to the deposition pressure and bias voltage.

\section{Experimental Procedure}

\subsection{Substrates Fabrication of Coating}

Disc substrates of STS 304 with diameter of $30 \mathrm{~mm}$ were used, along with a $\mathrm{Si}(400)$ wafer with dimensions of $20 \times 30$
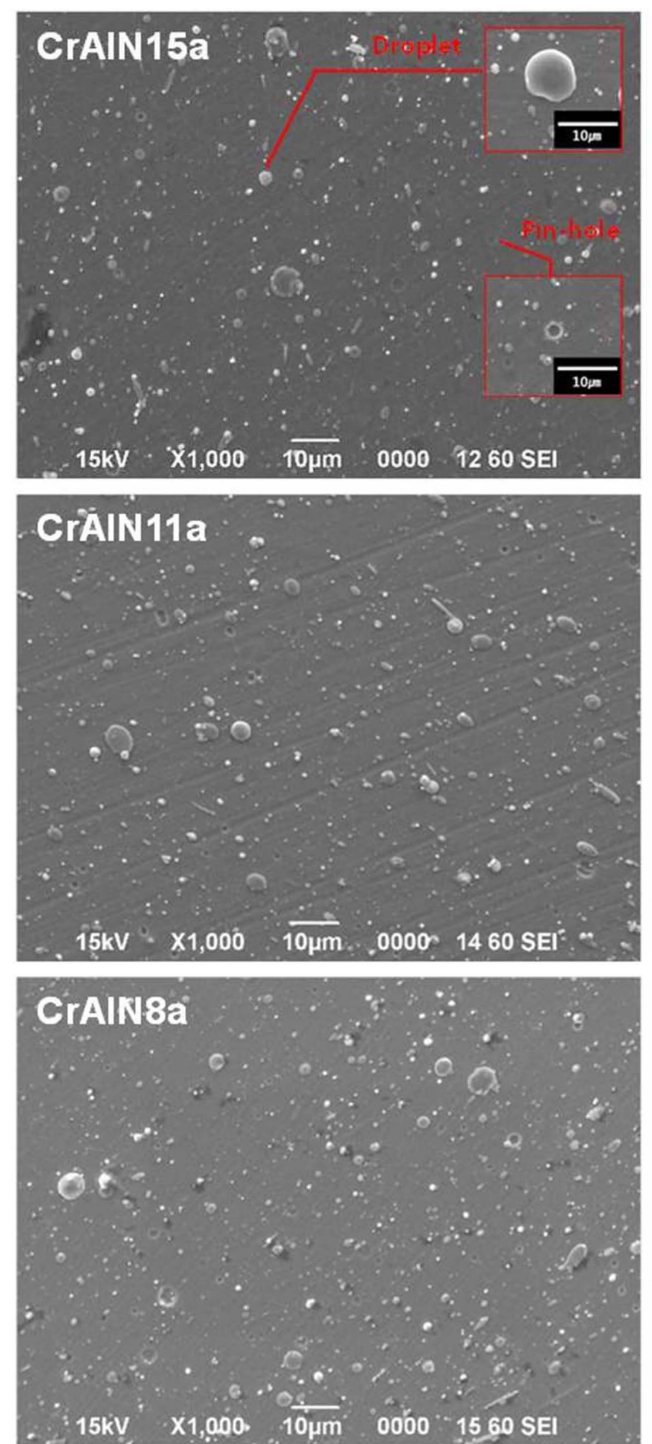

$\mathrm{mm}$. The surface of the substrate was polished with 1500 mesh to obtain an roughness of $0.05 \mu \mathrm{m}$ or less. The substrates and silicon wafer cleared by sonication using ethanol and acetone, followed by oven drying. $\operatorname{Cr}(99.9 \%)$ was installed as the arc ion plating source while $\mathrm{Al}(99.9 \%)$ was installed as the sputtering source. The distance between

Table 1. Deposition Parameter of Cr-Al-N Coatings

\begin{tabular}{ccccc}
\hline Sample & $\begin{array}{c}\text { Working } \\
\text { pressure } \\
\text { (mTorr) }\end{array}$ & $\begin{array}{c}\text { Substrate } \\
\text { bais } \\
\text { (V) }\end{array}$ & $\begin{array}{c}\text { AIP } \\
\text { current } \\
(\mathrm{A})\end{array}$ & $\begin{array}{c}\text { UBM } \\
\text { power } \\
(\mathrm{W})\end{array}$ \\
\hline CrAlN15a & 15 & -100 & 60 & $500 \pm 10$ \\
CrAlN15b & 15 & -300 & 60 & $500 \pm 10$ \\
CrAlN11a & 11 & -100 & 60 & $500 \pm 10$ \\
CrAlN11b & 11 & -300 & 60 & $500 \pm 10$ \\
CrAlN8a & 8 & -100 & 60 & $500 \pm 10$ \\
CrAlN8b & 8 & -300 & 60 & $500 \pm 10$ \\
\hline
\end{tabular}
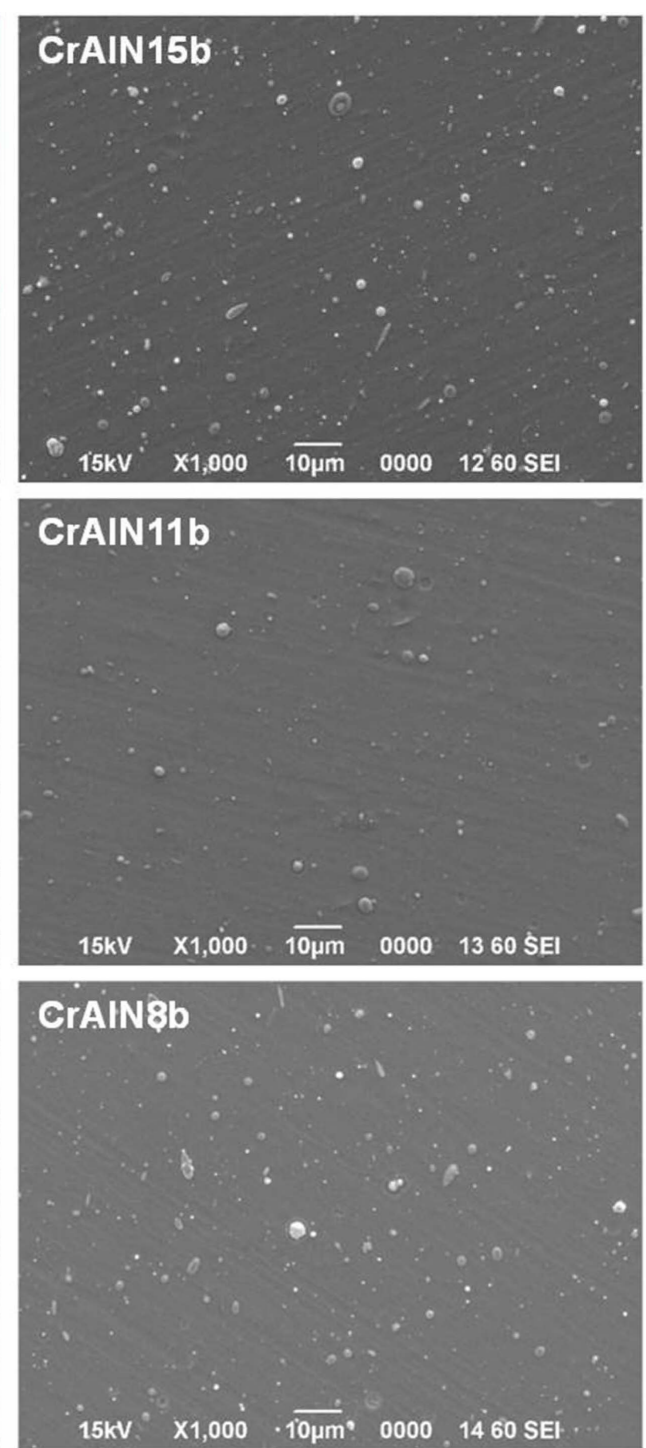

Fig. 1. Scanning electron micrographs of coating surface. 
each target and substrate were set at $90 \mathrm{~mm}$. The vacuum environment within the chamber before coating was set at 4.5E-5 torr through pumping out, followed by heating to $300^{\circ} \mathrm{C}$. The substrate and target before coating were ion cleaned using argon gas into the chamber until the chamber pressure reached $8 \mathrm{~m}$ torr. For the adhesion of the coating, the $\mathrm{Cr}$ interlayer was deposited for 10 minutes under the $8 \mathrm{~m}$ torr argon atmosphere. The deposition pressure was adjusted to $15 \mathrm{~m}$ torr, $11 \mathrm{~m}$ torr, and $8 \mathrm{~m}$ torr so that the ratio of the nitrogen and argon gases in the coating process was $50 \sim 60 \%$; to fabricate the $\mathrm{Cr}-\mathrm{Al}-\mathrm{N}$ coating, the bias voltage for each deposition pressure was applied for 30 minutes within the range of $-100 \sim-300 \mathrm{~V}$. Table 1 shows the process conditions.

\subsection{Characteristic of Coating}

Scanning electron microscopy (JSM-6390, JELO, Japan) and field-emission scanning electron microscopy (S-4700, HITACHI, Japan) were used to observe the coating surface and cross sectional mictostructure. X-ray diffraction (D/ max-2500, Rigaku, Japan) was used to analyze the crystal structure of coating, a diffraction pattern of $30 \sim 80^{\circ}$ range and scan rate of $2 \%$ min under the condition of $40 \mathrm{kV}, 100$ $\mathrm{mA}$ using $\mathrm{Cu} \mathrm{k} \alpha$. Composition analysis of the coating and measurement of the bonding energy were performed using X-ray photoelectron spectroscopy (PHI 5000 VersaProbe $^{\mathrm{TM}}$, ULVAC-PHI, Japan), in which the measurement was carried out using $\mathrm{Al} \mathrm{k} \alpha$ radiation $(\mathrm{h} v=1486.6 \mathrm{eV})$, followed by calibration at C1s $(284.6 \mathrm{eV})$.

\section{Results and Discussion}

Figure 1 shows the coating surface microstructure. The droplets and pinholes from the arc ion plating can be
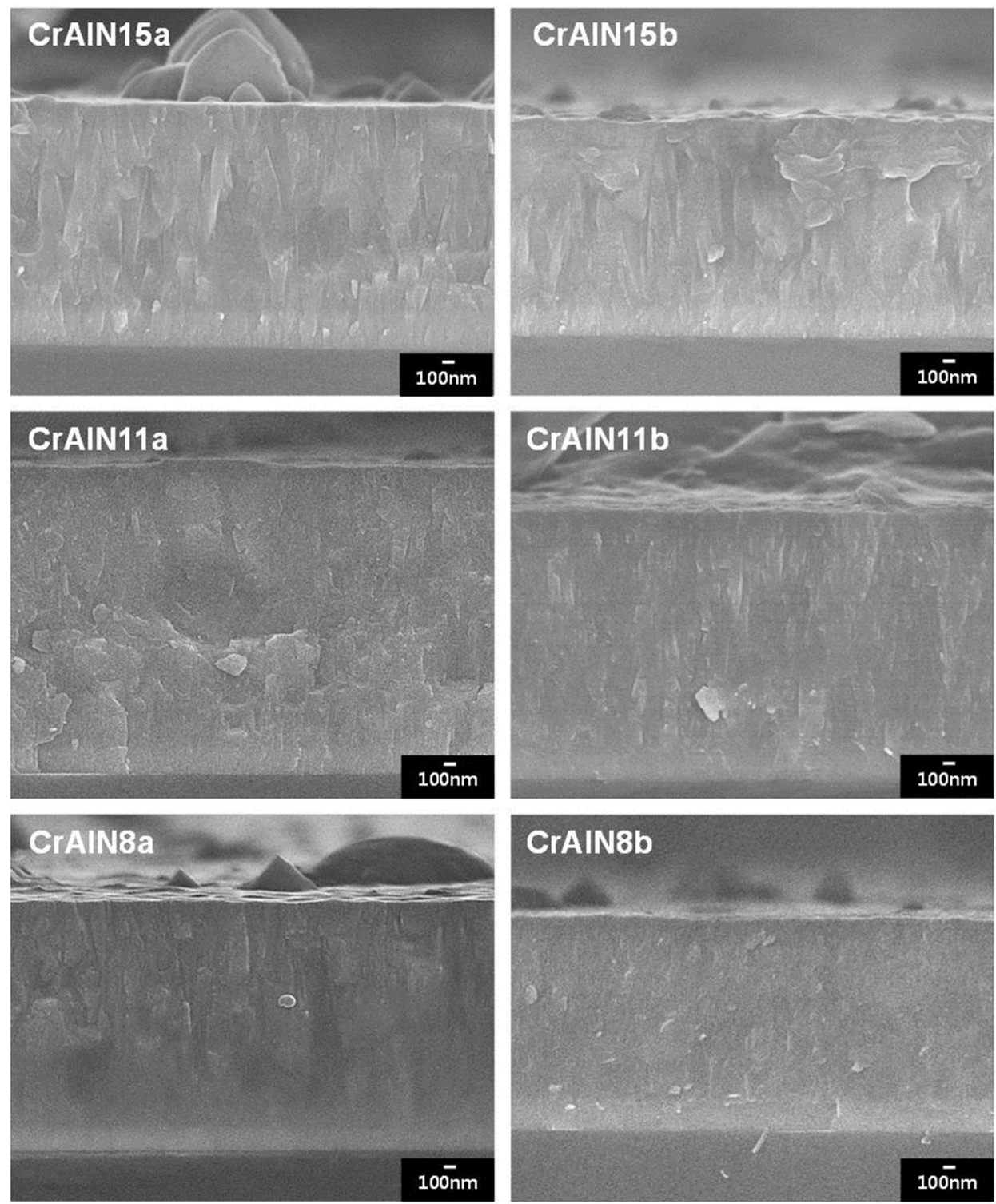

Fig. 2. Cross-sectional view of the films by FESEM. 
observed on the Cr-Al-N coating surface. The droplets and pinholes were observed on the surfaces of the CrAlN15a, CrAlN11a, and CrAlN8a, which used the same bias voltage of $-100 \mathrm{~V}$. The number and size of droplets decreased for CrAlN15b, CrAlN11b, and CrAlN8b, which used an increased bias voltage of $-300 \mathrm{~V}$. The decrease in droplets according to the bias voltage increase can be explained through two factors. First, the arc ion plating method of deposition has a high ionization efficiency of about $80 \sim 90 \%$, but deposition without applying the bias voltage results in partial ionization of $\mathrm{Cr}$ and $\mathrm{N}_{2}$, so that the $\mathrm{Cr}$ lumps (droplets) that were not ionized were deposited on the surface. ${ }^{21,23)}$ However, when bias voltage was applied, the plasma can be accelerated by the given electrical field and the droplets weakly bonded to the surface can be removed by the impact energy between the incident ions and the coating layer. ${ }^{24)}$ Another factor is related to the repulsion force between the droplet and the substrate which is negatively charged. The droplet before deposition on the coating surface exists as a colloid form, with ions and neutrons within a plasma. Ions and neutrons absorbed into the droplets result in the droplets having a charge; electrons (smaller mass) are mainly absorbed into the droplets, which then have net negative charges. ${ }^{25-27)}$ These droplets can form a repulsion force aganist the plasma sheath around the substrate, reducing the number of droplets on the coating surface. ${ }^{25,28)}$

The coating cross section is shown in Fig. 2, in which the Cr interlayer deposition of $0.2 \sim 0.3 \mu \mathrm{m}$ can be observed. CrAlN15a and CrAlN15b coatings are grown into the columnar structures, which the column width expanded with increasing of the thickness and the coating thicknesses decreased from $2.3 \mu \mathrm{m}$ to $1.6 \mu \mathrm{m}$ according to the bias increase. The microstructure of CrAlN11a and CrAlN11b coatings were observed as if columnar growth was inhibitated and the coating thicknesses decreased from $2.1 \mu \mathrm{m}$ to $1.5 \mu \mathrm{m}$ as the bias voltage increased. CrAlN8a and CrAlN8b did not clearly exhibit columnar growth and had coating thicknesses in a range of $2.3 \mu \mathrm{m}$ to $2.0 \mu \mathrm{m}$. As the deposition pressure decreased under constant bias voltage, it was observed that the growth of columnar width decreased. This phenomenon was might determined to be due to the increase in the number of particles reaching the substrate under the relatively low deposition pressure. Also, when the bias voltage increased, the number of seeds which produced on the coating surface, increased and the nucleation growth decreased, resulting in a decrease in the particle size and an increase in the coating density.,29) Therefore, the decrease in the deposition pressure led to the decrease in growth of columnar width, and the coating thickness decreased due to the bias increase.

Figure 3 shows the X-ray diffraction graph of coatings. In Fig. 3(a), the $\mathrm{Cr}$ and $\mathrm{CrN}$ phase can be observed and $\mathrm{CrN}$ growth to (111), (200), (220), and (311) phase. The measurement results using the condition of $0.5 \% \mathrm{~min}$ if scan rate to observe the small peaks are shown in Fig. 3(b); the Cr, CrN, and $\mathrm{Cr}_{2} \mathrm{~N}$ phases were measured for all coatings. For the CrN deposited using PVD, it has been reported that the most stable plane of (200) grew first, followed by (111) or (220), due to the increase in strain energy according to the bias effect or the thickness increase. ${ }^{22,30)}$ In order to investi-
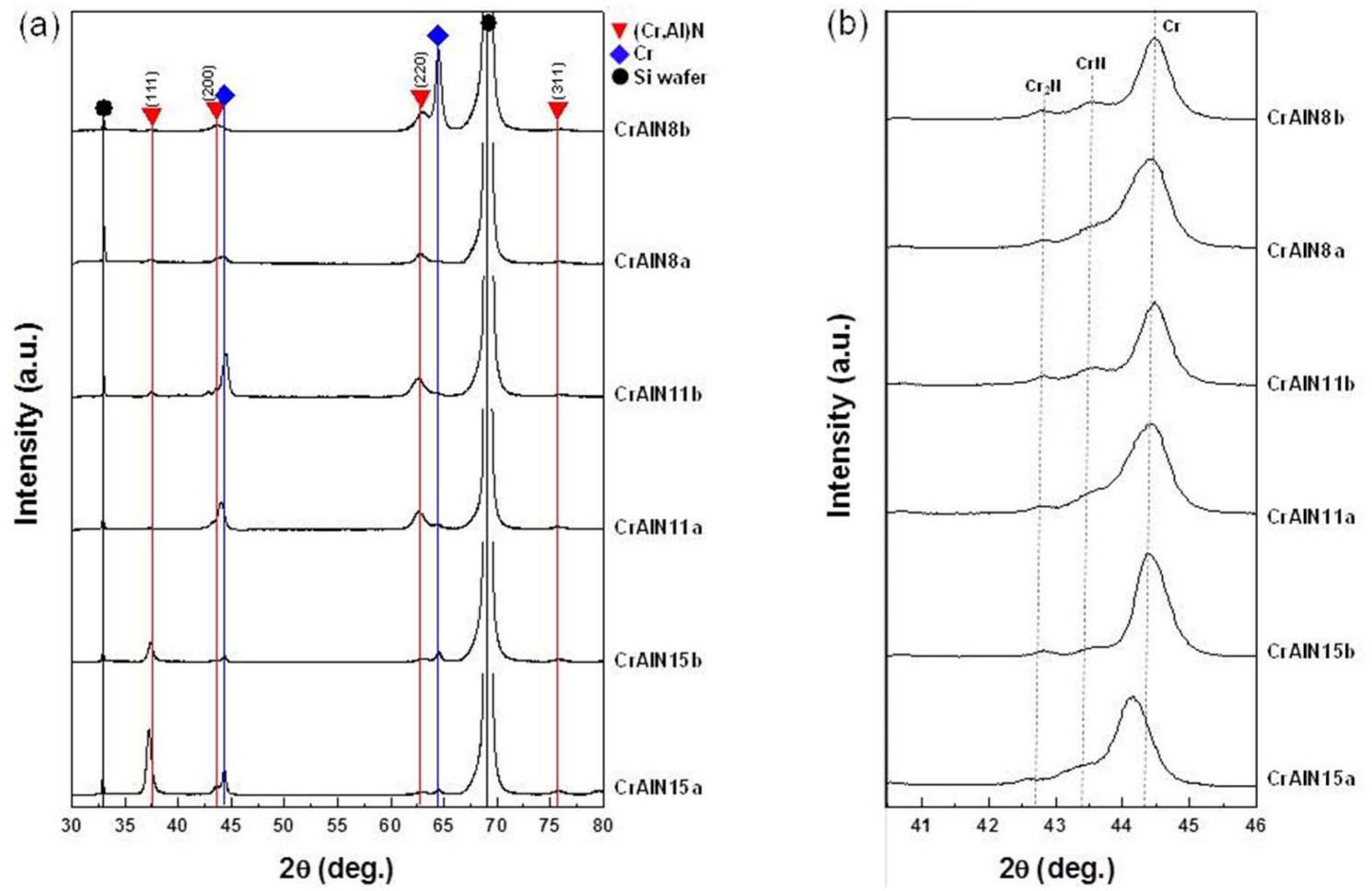

Fig. 3. X-ray diffraction patterns of coatings for (a) $30^{\circ} \sim 80^{\circ}$, (b) $40.5^{\circ} \sim 48^{\circ}$. 


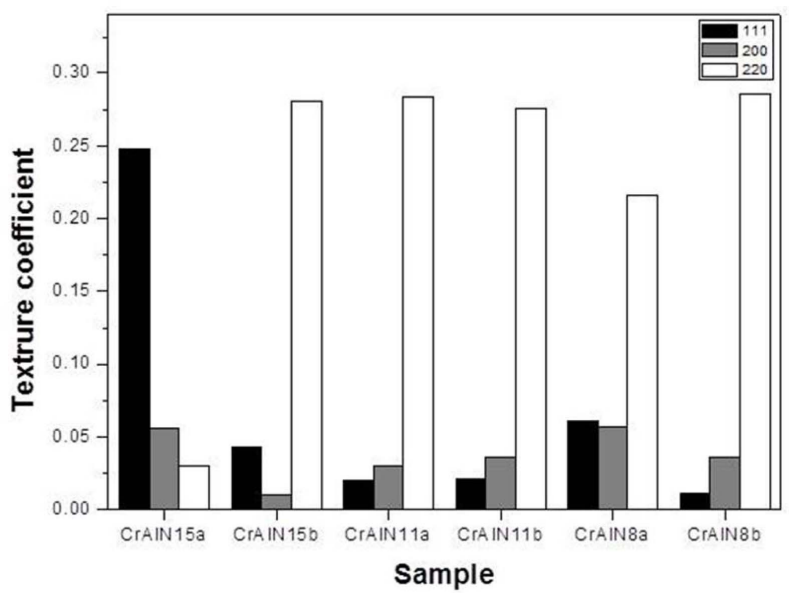

Fig. 4. Texture coefficient of Cr-Al-N coatings.

gate the orientation due to the bias voltage for the (111), (200), and (220) surfaces of $\mathrm{CrN}$ in the Cr-Al-N coating, the calculation value using the Harris texture coefficient equation is shown in Fig. $4 .^{20)}$ The diffraction pattern of the CrAl-N coating shifted to a low angle (29); this was might determined to be due to the solution of $\mathrm{Al}$ within the $\mathrm{CrN}$ lattice or the penetration of $\mathrm{Al}$ to the $\mathrm{Cr}$ lattice position in CrN ${ }^{31)}$ CrAlN15a lattice showed prepared growth to (111), while all the other $\mathrm{Cr}-\mathrm{Al}-\mathrm{N}$ coatings showed priority growth to (220). This result was thought to be due to the effect of strain energy on the coating layer due to the increases in the deposition pressure and bias voltage..$^{30-32)}$

Although $\mathrm{Cr}, \mathrm{Cr}_{2} \mathrm{~N}$, and $\mathrm{CrN}$ were measured in the XRD analysis results, no diffraction pattern from $\mathrm{Al}$ was observed. Thus, XPS was used to observe the bonding of $\mathrm{Al}$, $\mathrm{AlN}$, and $(\mathrm{Cr}, \mathrm{Al}) \mathrm{N}$ due to $\mathrm{Al}$ and to analyze the composition of the coating. Table 2 shows the composition analysis results for the coating and Fig. 5 shows the bonding ener-
Table 2. Composition of Cr-Al-N Coatings (at\%)

\begin{tabular}{cccc}
\hline Sample & Cr (at\%) & Al (at\%) & N (at\%) \\
\hline CrAlN15a & 30.1 & 30.1 & 39.8 \\
CrAlN15b & 29.6 & 33.7 & 36.7 \\
CrAlN11a & 35.2 & 30.4 & 35.2 \\
CrAlN11b & 26.1 & 40.3 & 33.5 \\
CrAlN8a & 23.2 & 38.1 & 38.6 \\
CrAlN8b & 36.9 & 31.8 & 31.3 \\
\hline
\end{tabular}

gies of $\mathrm{Cr}, \mathrm{Al}$, and $\mathrm{N}$ for each coating. From Table 2, it can be observed that deposition was carried out with $23.2 \sim 36.9$ at\% $\mathrm{Cr}, 30.1 \sim 40.3$ at $\% \mathrm{Al}$, and $31.3 \sim 39.8$ at $\% \mathrm{~N}$ for the $\mathrm{Cr}-$ Al-N coating. Fig. 5(a) shows the $\mathrm{Cr} 2 \mathrm{p}$ bonding energy; the bonding energies of $(\mathrm{Cr}, \mathrm{Al}) \mathrm{N}, \mathrm{CrN}$, and $\mathrm{Cr}_{2} \mathrm{~N}$ were observed at $\mathrm{Cr} 2 \mathrm{p} 3 / 2574.6 \mathrm{eV}, \mathrm{Cr} 2 \mathrm{p} 3 / 2575.5 \mathrm{eV}$, and $\mathrm{Cr} 2 \mathrm{p} 3 / 2577.0$ $\mathrm{eV}$, respectively. Moreover, $\mathrm{Cr}-\mathrm{O}$ bonding was observed in the oxide film formation on the coating surface. Fig. 5(b) shows the $\mathrm{Al}$ bonding energy, and the bonding energy of $\mathrm{Cr}$ $3 \mathrm{~s}$ was also observed above $75 \mathrm{eV}$. For all coating specimens, $\mathrm{Al},(\mathrm{Cr}, \mathrm{Al}) \mathrm{N}$, and $\mathrm{AlN}$ were observed at $\mathrm{Al} 2 \mathrm{p} 73.3 \mathrm{eV}, 73.6$ $\mathrm{eV}$, and $78.2 \mathrm{eV}$, respectively. Fig. 5(c) shows the $\mathrm{N} 1 \mathrm{~s}$ bonding energy; $(\mathrm{Cr}, \mathrm{Al}) \mathrm{N}, \mathrm{CrN}$, and $\mathrm{AlN}$ were measured. It is known that, in the XPS analysis, the bonding energy generally increases when bonding takes place with atoms of high electronegativity. The diffraction pattern of $\mathrm{Cr}$, obtained through XRD analysis, was might determine to be due to the effect of the $\mathrm{Cr}$ interlayer deposited between the coating and the substrate.

\section{Conclusions}

Cr-Al-N coating was fabricated using a hybrid PVD system integrating the arc ion plating and unbalanced magne-
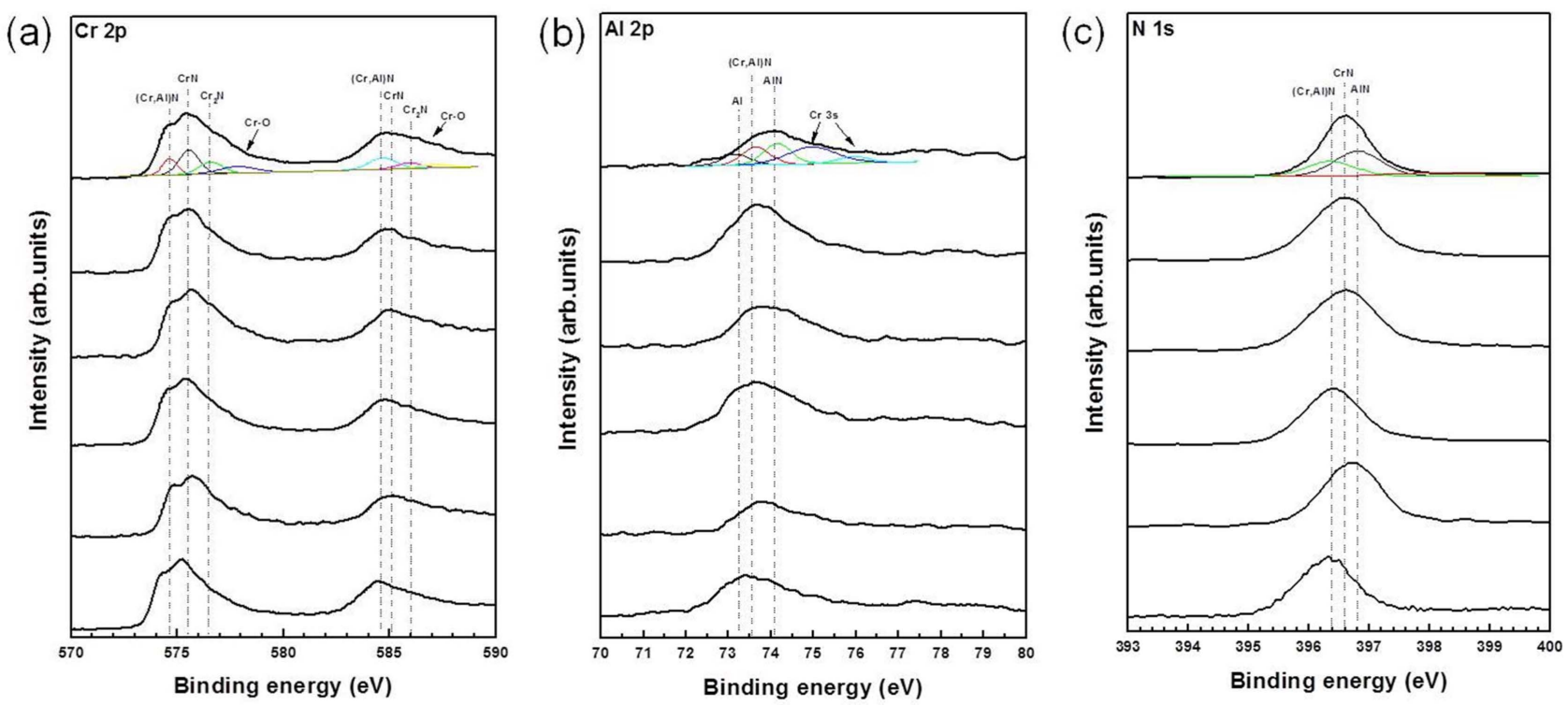

Fig. 5. XPS spectra of Cr-Al-N films (a) $\mathrm{Cr} 2 \mathrm{p}$, (b) $\mathrm{Al} \mathrm{2p}$, (c) N 1 s. 
tron sputtering methods. The deposition pressures were charged to $15 \mathrm{~m}$ torr, $11 \mathrm{~m}$ torr, and $8 \mathrm{~m}$ torr, and argon and nitrogen gases were mixed to carry out deposition at the condition of nitrogen gas ratio of at least $50 \%$. Deposition was conducted with bias voltages of $-100 \mathrm{~V}$ and $-300 \mathrm{~V}$, and the phase formation and microstructure of the coating layer according to the bias voltage and deposition pressure were observed. From the observation of the microstructure, it revealed that the size and number of droplets on the coating surface decreased as the bias voltage increased, while the deposition thickness decreased. Columnar growth was observed in the coating cross section and columnar with small width was observed as the deposition pressure decreased. In the X-ray diffraction analysis, the $\mathrm{CrN}$ phase was deposited with (111), (200), and (220) planes, and prepared growth of (111) and (220) planes are observed. All of the $\mathrm{Cr}-\mathrm{Al}-\mathrm{N}$ coating diffraction patterns shifted to low angle (20); this phenomenon was thought to be due to the solution of $\mathrm{Al}$ within the $\mathrm{CrN}$ lattice or substitution of $\mathrm{Al}$ in the $\mathrm{Cr}$ lattice position. From the XPS analysis, the deposition of the Cr-Al-N coating with $\mathrm{Cr} 23.2 \sim 36.9$ at\%, Al $30.1 \sim 40.3$ at\%, and N $31.3 \sim 39.8$ at\% was identified and bonding of $\mathrm{CrN}, \mathrm{Cr}_{2} \mathrm{~N}$, and $(\mathrm{Cr}, \mathrm{Al}) \mathrm{N}$ was observed.

\section{REFERENCES}

1. S. Veprek and M. J. Veprek-Heijman, "Industrial Applications of Superhard Nanocomposite Coatings," Surf. Coat. Technol., 202 [21] 5063-73 (2008).

2. Y. Chim, X. Ding, X. Zeng, and S. Zhang, "Oxidation Resistance of TiN, CrN, TiAlN and CrAlN Coatings Deposited by Lateral Rotating Cathode Arc," Thin Solid Films, 517 [17] 4845-49 (2009).

3. K.-D. Bouzakis, N. Michailidis, S. Gerardis, G. Katirtzoglou, E. Lili, M. Pappa, M. Brizuela, A. Garcia-Luis, and R. Cremer, "Correlation of the Impact Resistance of Variously Doped CrAlN PVD Coatings with their Cutting Performance in Milling Aerospace Alloys," Surf. Coat. Technol., 203 [5] 781-85 (2008).

4. S. Zhang, L. Wang, Q. Wang, and M. Li, "A Superhard CrAlSiN Superlattice Coating Deposited by Multi-Arc Ion Plating: I. Microstructure and Mechanical Properties," Surf. Coat. Technol., 214 160-67 (2013).

5. J. Romero, M. Gómez, J. Esteve, F. Montalà, L. Carreras, M. Grifol, and A. Lousa, "CrAlN Coatings Deposited by Cathodic Arc Evaporation at Different Substrate Bias," Thin Solid Films, 515 [1] 113-17 (2006).

6. E. Spain, J. Avelar-Batista, M. Letch, J. Housden, and B. Lerga, "Characterisation and Applications of Cr-Al-N Coatings," Surf. Coat. Technol., 200 1507-13 (2005).

7. X.-Z. Ding and X. Zeng, "Structural, Mechanical and Tribological Properties of CrAlN Coatings Deposited by Reactive Unbalanced Magnetron Sputtering," Surf. Coat. Technol., 200 1372-76 (2005).

8. Z. Li, P. Munroe, Z.-T. Jiang, X. Zhao, J. Xu, Z.-F. Zhou, J.-Q. Jiang, F. Fang, and Z.-H. Xie, "Designing Superhard, Self-Toughening CrAlN Coatings through Grain Boundary Engineering," Acta Mater., 60 5735-44 (2012).
9. J. Lin, B. Mishra, J. Moore, and W. Sproul, "Microstructure, Mechanical and Tribological Properties of $\mathrm{Cr}_{1-\mathrm{x}} \mathrm{Al}_{\mathrm{x}} \mathrm{N}$ Films Deposited by Pulsed-Closed Field Unbalanced Magnetron Sputtering (P-CFUBMS)," Surf. Coat. Technol., 201 [7] 4329-34 (2006).

10. H. C. Barshilia, N. Selvakumar, B. Deepthi, and K. Rajam, "A Comparative Study of Reactive Direct Current Magnetron Sputtered CrAlN and CrN Coatings," Surf. Coat. Technol., 201 [6] 2193-201 (2006).

11. D. M. Mattox, Handbook of Physical Vapor Deposition (PVD) Processing; pp. 384-405, Elsevier, New Mexico, 2010.

12. S.-Y. Chun, "Microstructure and Mechanical Properties of Nanocrystalline TiN Films through Increasing Substrate Bias," J. Korean Ceram. Soc., 47 [6] 479-84 (2010).

13. H. W. Ryu, G. P. Choi, W.-S. Noh, Y.-J. Park, and J. S. Park, "Effect of Oxygen Flow Ratio on the Crystallographic Orientation of NiO Thin Films Deposited by RF Magnetron Sputtering," J. Korean Ceram. Soc., 41 [2] 106-10 (2004).

14. J. Musil and S. Kadlec, "Reactive Sputtering of TiN Films at Large Substrate to Target Distances," Vacuum, 40 [5] 435-44 (1990).

15. S.-K. Tien, C.-H. Lin, Y.-Z. Tsai, and J.-G. Duh, "Effect of Nitrogen Flow on the Properties of Quaternary CrAlSiN Coatings at Elevated Temperatures," Surf. Coat. Technol., 202 [4] 735-39 (2007).

16. T. Elangovan, P. Kuppusami, R. Thirumurugesan, V. Ganesan, E. Mohandas, and D. Mangalaraj, "Nanostructured CrN Thin Films Prepared by Reactive Pulsed DC Magnetron Puttering," Mater. Sci. Eng., B, 167 [1] 17-25 (2010).

17. M. Egawa, K. I. Miura, M. Yokoi, and I. Ishigami, "Effects of Substrate Bias Voltage on Projection Growth in Chromium Nitride Films Deposited by Arc Ion Plating," Surf. Coat. Technol., 201 [9] 4873-78 (2007).

18. E. Forniés, R. E. Galindo, O. Sánchez, and J. Albella, "Growth of CrNx Films by DC Reactive Magnetron Sputtering at Constant $\mathrm{N}_{2} / \mathrm{Ar}$ Gas Flow," Surf. Coat. Technol., 200 [20] 6047-53 (2006).

19. J. Bujak, J. Walkowicz, and J. Kusiński, "Influence of the Nitrogen Pressure on the Structure and Properties of (Ti, Al)N Coatings Deposited by Cathodic Vacuum Arc PVD Process," Surf. Coat. Technol., 180 150-57 (2004).

20. C. Gautier and J. Machet, "Study of the Growth Mechanisms of Chromium Nitride Films Deposited by Vacuum ARC Evaporation," Thin Solid Films, 295 [1-2] 43-52 (1997).

21. M. Li and F. Wang, "Effects of Nitrogen Partial Pressure and Pulse Bias Voltage on (Ti,Al)N Coatings by Arc Ion Plating," Surf. Coat. Technol., 167 [2] 197-202 (2003).

22. J.-W. Lee, S.-K. Tien, and Y.-C. Kuo, "The Effects of Pulse Frequency and Substrate Bias to the Mechanical Properties of CrN Coatings Deposited by Pulsed DC Magnetron Sputtering," Thin Solid Films, 494 [1] 161-67 (2006).

23. X. Wan, S. Zhao, Y. Yang, J. Gong, and C. Sun, "Effects of Nitrogen Pressure and Pulse Bias Voltage on the Properties of Cr-N Coatings Deposited by Arc Ion Plating," Surf. Coat. Technol., 204 [11] 1800-10 (2010).

24. K.-L. Chang, S.-C. Chung, S.-H. Lai, and H.-C. Shih, "The Electrochemical Behavior of Thermally Oxidized CrN 
Coatings Deposited on Steel by Cathodic Arc Plasma Deposition," Appl. Surf. Sci., 236 [1] 406-15 (2004).

25. M. Huang, G. Lin, Y. Zhao, C. Sun, L. Wen, and C. Dong, "Macro-Particle Reduction Mechanism in Biased Arc Ion Plating of TiN," Surf. Coat. Technol., 176 [1] 109-14 (2003).

26. J. J. Wu and R. J. Miller, "Measurements of Charge on Submicron Particles Generated in a Sputtering Process," J. Appl. Phys., 67 [2] 1051-54 (1990).

27. A. Melzer, T. Trottenberg, and A. Piel, "Experimental Determination of the Charge on Dust Particles Forming Coulomb Lattices," Phys. Lett. A, 191 [3-4] 301-8 (1994).

28. R. Boxman and S. Goldsmith, "Macroparticle Contamination in Cathodic Arc Coatings: Generation, Transport and Control," Surf. Coat. Technol., 52 [1] 39-50 (1992).

29. Y. Chunyan, T. Linhai, W. Yinghui, W. Shebin, L. Tianbao, and X. Bingshe, "The Effect of Substrate Bias Volt- ages on Impact Resistance of CrAlN Coatings Deposited by Modified Ion Beam Enhanced Magnetron Sputtering," Appl. Surf. Sci., 255 [7] 4033-38 (2009).

30. H.-S. Jang, Y.-S. Kim, J.-H. Lee, H.-G. Chun, Y.-Z. You, and D.-I. Kim, "Effect of Substrate Bias Voltage on the Growth of Chromium Nitride Films," Korean J. Mater. Res., 17 [11] 618-21 (2007).

31. I.-W. Park, D. S. Kang, J. J. Moore, S. C. Kwon, J. J. Rha, and K. H. Kim, "Microstructures, Mechanical Properties, and Tribological Behaviors of Cr-Al-N, Cr-Si-N, and CrAl-Si-N Coatings by a Hybrid Coating System," Surf. Coat. Technol., 201 [9] 5223-27 (2007).

32. J. Pelleg, L. Zevin, S. Lungo, and N. Croitoru, "ReactiveSputter-Deposited TiN Films on Glass Substrates," Thin Solid Films, 197 [1-2] 117-28 (1991). 